\section{AVESSO DA ESCRAVIZACÃO OU LIBERDADES PRECARIZADAS: UM ESTUDO SOBRE A CONDIÇÃO LEGAL DAS PESSOAS ESCRAVIZADAS NO BRASIL QUE FUGIAM EM DIREÇÃO À BOLÍVIA $(1826-1845)^{1}$}

- Newman Di Carlo Caldeira ${ }^{2}$

Universidade Federal de Uberlândia(campus Pontal) Ituiutaba - Minas Gerais - Brasil

\title{
Resumo
}

Por meio da reunião de informações contidas nas correspondências diplomáticas, troca de avisos entre as autoridades brasileiras, orientações dos governantes bolivianos aos seus subordinados e fontes legislativas de ambos os Estados, este artigo se propõe a discutir a precariedade de uma possível forma de alforria, ou, ao menos, as implicações das movimentações internacionais de fuga na condição legal dos indivíduos escravizados após cruzarem as linhas de fronteira da província de Mato Grosso em direção à Bolívia. O exame das múltiplas experiências decorrentes do cruzamento entre o trabalho escravizado e as ideias e práticas de liberdade, presentes no imaginário dos prófugos oriundos do lado brasileiro, demonstrarão a importância da mobilidade espacial para a modificação dos campos de possibilidade dos diversos agentes sociais envolvidos diretamente ou indiretamente nas práticas de fuga. Nos casos analisados, as evasões, travessias e fugas não asseguraram necessariamente a aquisição da liberdade para os envolvidos, mas, sim, espaços de autonomia que muitas vezes levavam os fugitivos a viverem sob um limbo jurídico em função do desrespeito em relação às legislações existentes em ambos os lados da fronteira.

\section{Palavras-chave}

Trabalho escravizado - Movimentações internacionais de fuga - Liberdade precarizada Negociações diplomáticas - Província de Mato Grosso.

\footnotetext{
1 Artigo não publicado em plataforma de preprint. Todas as fontes e toda a bibliografia empregadas são referidas no artigo. Registra-se agradecimento ao Conselho Nacional de Desenvolvimento Científico e Tecnológico (CNPq) pelo apoio financeiro prestado à pesquisa.

2 Pós-doutorado no Departamento de História da Faculdade de Filosofia, Letras e Ciências Humanas da Universidade de São Paulo - FFLCH/USP, sob supervisão da Professora Stella Maris Franco. Professor do curso de História do Instituto de Ciências Humanas do Pontal (ICHPO), da Universidade Federal de Uberlândia, Ituiutaba, Minas Gerais, Brasil.
} 


\begin{abstract}
Through the gathering of information contained in diplomatic correspondence, exchange of notices among Brazilian authorities, orientation of Bolivian rulers to their subordinates, and legislative sources from both states, this article proposes to discuss the precariousness of a possible form of manumission, or, at least, the implications of international escape movements on the legal status of enslaved individuals after crossing the border lines of the province of Mato Grosso towards Bolivia. The examination of the multiple experiences resulting from the intersection between enslaved work and the ideas and practices of freedom presents in the imaginary of enslaved people from the Brazilian side will demonstrate the importance of spatial mobility for modifying the fields of possibility of the various social agents involved directly or indirectly in escape practices. In the cases analyzed, evasion, crossing and escape did not necessarily ensure the acquisition of freedom for those involved, but rather spaces of autonomy that often led fugitives to live under a legal limbo due to disrespect for both sides of the border.
\end{abstract}

\title{
Keywords
}

Enslaved labor - International moviments of escape - Precarious liberty - Diplomatic $\mathrm{Ne}$ gotiations - Province of Mato Grosso. 
Prosper Cambray havia percorrido aquela região muitas vezes, perseguindo fugitivos com outros milicianos da Marechaussée. Sabia decifrar os sinais da natureza, pegadas que seriam invisíveis a outros olhos, podia seguir um rastro como o melhor sabujo, farejar o medo e o suor de uma presa a várias horas de distância, enxergar de noite como os lobos e até mesmo adivinhar uma rebelião antes que explodisse e acabar com ela. Vangloriava-se de que, sob seu comando, poucos escravos tinham fugido de Saint-Lazare. Seu método consistia em lhes destruir a alma e a vontade. Nada como o medo e o cansaço para vencer a sedução da liberdade. Produzir, produzir, produzir até o último suspiro, que não tardava muito a chegar, porque lá ninguém envelhecia os ossos (...). ${ }^{3}$

O trecho selecionado de um conhecido romance escrito por Isabel Allende ilustra algumas das expectativas conflitantes que se faziam presentes no interior de um regime de trabalho que se pretendia de mando absoluto. ${ }^{4}$ Por mais que os proprietários e seus agentes tencionassem "destruir a alma e a vontade" dos escravizados, a "sedução da liberdade" continuava se perpetuando no cotidiano da instituição. Embora a esperança de conseguir melhores condições de vida e de trabalho precisasse ser dissimulada em meio às extenuantes jornadas de sobrevivência, os apelos em favor da liberdade certamente se mostravam fortes nas mentes e nos corações dos que optavam pela fuga como um mecanismo de mudança (nos casos bem-sucedidos). Se Stuart Schwartz considera as evasões das pessoas escravizadas como algo inerente ao sistema escravista (SCHWARTZ, 2001, p. 220-21), Neil Roberts as interpreta como uma chave importante para a reelaboração dos conceitos de escravidão e de liberdade (ROBERTS, 2015. p. 9-10).

Busca-se nortear essa análise acerca das movimentações das pessoas escravizadas oriundas do Brasil para a Bolívia a partir do diagnóstico feito por Roberts. Em Freedom as Marronage, o autor defende a necessidade de serem desenvolvidas mais categorias e distinções a respeito dos contextos transitórios que remetem à passagem da condição de escravizado à de pessoa livre. Uma das teses centrais da obra de Roberts se concentra no conceito de liber-

\footnotetext{
3 ALLENDE, 2011, p. 56. [Grifos nossos].

${ }^{4}$ LIMA; GRINBERG; REIS, 2018, p. 9. Ao adotarem uma perspectiva comparativa, os autores descreveram de modo preciso tanto as condições de vida de uma pessoa escravizada nas américas, quanto à dos servos na Rússia. Será reproduzida parte da definição proposta, segundo a qual os indivíduos estariam "submetidos a regimes de imobilidade não só social, mas espacial e geográfica, a distintas formas de dependência, à hereditariedade de sua condição, enredados em formas complexas de coerção jurídica e moral, em múltiplos sistemas de propriedade de terra".
} 
dade, considerado pelo autor como uma palavra-chave na cultura política e no pensamento modernos. A argumentação procura refutar alguns dos pressupostos contidos nas obras dos pensadores modernos, que tendem a analisar o conceito a partir das liberdades dos poderosos e dos privilegiados. A despeito da ausência das experiências modernas ligadas aos processos de escravização ou da própria agência dos escravizados nas teorias políticas, a obra de Roberts desconsidera a escravidão ou os processos de escravização como metáforas da ausência de liberdade.

O autor procura descortinar a perspectiva dos agentes sociais escravizados, particularmente de ascendência africana nas américas durante a Era da Revolução, algo inexplorado enquanto recurso para se pensar a liberdade dentro da teoria política. A questão que Roberts se propõe a responder pode ser resumida da seguinte maneira: quais os significados de se teorizar a respeito da liberdade a partir das vivências dos escravizados?

A inovação proposta pelo autor parte de uma abordagem que procura analisar e diferenciar as movimentações conhecidas como marronage, ou seja, os tipos de fuga, sua natureza e limitações. Freedom as Marronage examina o espaço liminar e transitório assumido pelas fugas com a intenção de sustentar que a liberdade estaria fundamentalmente localizada dentro desse espaço de fuga definitiva ou perpétua. Essa nova conceituação de liberdade decorreria da existência de um imaginário não-soberano de liberdade, que orientou os destinos de milhares de pessoas escravizadas em suas tentativas de escapar do arbítrio de regimes de vida e de trabalho que lhes era imposto (ROBERTS, 2015, p. 116).

O autor subdividiu as principais teorias da liberdade de duas maneiras: negativa e positiva (ROBERTS, 2015, p. 13-15). Roberts considera que a obra de teóricos como Thomas Hobbes e Isaiah Berlin representaria as teorias negativas, enquanto Hannah Arendt e Jean-Jacques Rousseau fariam parte dos teóricos que percebem a liberdade como algo positivo. Resumidamente, a questão principal das teorias negativas se concentra na definição da liberdade como ausência de dominação, enquanto as positivas se limitariam a entender a liberdade como possibilidade de autodomínio e de agência participativa. Em comum, segundo Roberts, estaria a rejeição da ideia e da prática de liberdade enquanto processos ligados às movimentações de fuga das pessoas escravizadas. $\mathrm{O}$ autor ainda aponta a negação da agência dos escravizados nas respectivas teorias. No lugar das limitações percebidas em ambas as correntes teóricas, Neil Roberts procura compreender o significado mais amplo das experiências de fuga e resistência dos escravizados para a teoria política (ROBERTS, 2015, p. 4).

Na esteira da obra de Roberts, mesmo com pretensões mais modestas tanto a nível geográfico por analisar um espaço menos abrangente que sua 
obra, quanto na apresentação de conclusões que não generalizam as perspectivas apresentadas, procura-se demonstrar dentro das limitações metodológicas impostas pelas fontes, a importância das movimentações de fuga para os escravizados brasileiros em suas tentativas de modificar as próprias possibilidades. Para tanto, entendemos que o conhecido binômio cativeiro e liberdade, presente nos debates jornalísticos, políticos e jurídicos do Brasil oitocentista, muitas vezes não contempla inúmeras gradações que contribuíam para alargar os significados que podiam ser atribuídos às vivências inerentes à categoria de liberdade. ${ }^{5}$ Em função disso, partimos do pressuposto de que as práticas sociais assentadas nos processos de escravização e na manutenção de seres humanos na condição de escravizados, assim como suas respectivas libertações, não podem ser compreendidas como ambivalentes ou simétricas por inexistirem correspondências exatas ou sequer aproximadas entre ambos.

Em diferentes momentos e partindo de vieses teóricos e de metodologias distintas, os historiadores têm se dedicado a analisar experiências coletivas e individuais a respeito dos possíveis significados do cativeiro e da liberdade para as pessoas escravizadas. No entanto, mesmo nos casos em que os estudiosos lograram êxito em conhecer de modo mais apurado as condições de vida e de trabalho de escravizados ou dos libertos, a lacuna da experiência permanece em aberto, resultando em algo intangível: a noção relativa ao modo como tais vivências foram sentidas pelos envolvidos. As trajetórias de vida marcadas pelo encontro com alguma forma de liberdade ou de conquista de uma maior autonomia podem ser investigadas a partir do reconhecimento de seu caráter parcial pelos estudiosos. Da mesma forma, a vida em cativeiro foi experimentada enquanto algo particular e sem correlações.

\section{Fugas, passagens e travessias: as possibilidades abertas pela mobilidade territorial}

Os variados graus de autonomia e as formas de protesto experimentadas pelos escravizados a partir das brechas existentes tornaram a conquista da liberdade algo tangível, mesmo quando em cativeiro (FLORENTINO, 2005, p. 338). Para tanto, as fugas de caráter temporário ou não se apresentavam como uma alternativa capaz de fazer com que as pessoas escravizadas passassem a viver longe do alcance do Estado, de seus representantes e de seus

\footnotetext{
5 Em relação às diferentes concepções de liberdade, ver: SCOTT, 2005; PATTERSON, 1982, p. 209-61.
} 
sistemas judiciários, assim como dos proprietários ou amos. As travessias e passagens internacionais reforçavam essa perspectiva na medida em que os fugitivos conseguiram, em alguns casos, se colocar ou se manter fora do alcance do rigor das leis e das autoridades existentes em seus locais de origem.

Ademais, as movimentações de fuga agregavam em si novos significados para a concretização de uma liberdade possível, ainda que não reconhecida pelas autoridades envolvidas e fora das definições legais dos Estados que os acolhiam, nos casos internacionais. Ao migrarem, os fugitivos passavam a se sujeitar a um conjunto de leis e práticas sociais até então provavelmente desconhecidos da maioria dos prófugos, mas que, de todo modo, passariam a regular suas vidas e suas possibilidades. Mesmo sem conhecer os meandros jurídicos em relação à situação que enfrentariam ou possuírem garantias legais de que melhorariam suas condições de vida e de trabalho, muitos escravizados que habitavam o lado brasileiro escolheram essa modalidade de fuga. As oportunidades oferecidas pela mobilidade espacial certamente motivaram muitos escravizados a fugir.

As travessias internacionais, ainda que bem-sucedidas, resultavam, em algum momento, em algo provisório ou mesmo precarizado em função de as autoridades locais, regionais ou nacionais condicionarem à questão a entendimentos pessoais que não observavam princípios jurídicos mais gerais, como cartas constitucionais, códigos, ordens, decretos e regulamentos (DÍAZ VILLAMIL, [19--], p. 355-57). A ausência de consensos mínimos entre as esferas de governança, juntamente com as distâncias entre os departamientos bolivianos fomentaram o descumprimento de legislações vigentes no tocante às garantias dos estrangeiros asilados. Embora prevista a libertação dos indivíduos que buscassem asilo em território boliviano pela primeira carta constitucional, publicada em $1826,{ }^{6}$ a falta de unificação linguística e a publicidade falha na divulgação das normas aprovadas geraram conflitos de jurisdição entre as autoridades e incrementaram os possíveis desrespeitos em relação à condição legal dos recém-chegados. ${ }^{7}$

\footnotetext{
BOLÍVIA. Constituição Política da República da Bolívia, de 19/11/1826.

Arquivo Histórico do Itamaraty (AHI) 308/02/08 - Correspondência anexa ao ofício n. ${ }^{0}$ 5, de Cuiabá em 14/9/1835, em que os membros da Câmara Municipal da cidade de Mato Grosso se reuniram em sessão ordinária de 13 de julho de 1835 para pedir ao Imperador providências em relação aos casos de fuga de escravos em direção à República da Bolívia. Esse documento ainda menciona o caso de escravizados fugitivos oriundos do Brasil que teriam vendido a si próprios a cidadãos bolivianos, contrariando o disposto nas leis daquele Estado.
} 
A mobilidade de longa distância implicava em mais do que ter de lidar com regras, oportunidades e imposições existentes do outro lado da fronteira, sendo necessário considerar que os fugitivos teriam que percorrer locais inóspitos ou desconhecidos até chegar em seus destinos. Durante o trajeto, poderiam se deparar com paisagens que facilitariam ou não suas movimentações, como florestas, rios, serras, montanhas etc., comumente usadas como esconderijos pelos escravizados. Em suas passagens, os caminhos poderiam ser percorridos a pé, a nado ou de barco, dependendo das condições do terreno. A viabilidade da circulação estava sujeita às cheias dos rios, mas também aos insetos pestilentos e às febres letais, havendo ainda a necessidade de serem transpostos os obstáculos humanos, como as diversas etnias indígenas que habitavam os caminhos da travessia. Em função das circunstâncias, os indígenas poderiam se aliar aos quilombolas, da mesma forma que aos fugitivos que estivessem apenas de passagem, mas, segundo João José Reis e Flávio Gomes, os índios aparecem frequentemente associados às tropas repressoras em razão das recompensas prometidas pelas autoridades. Além disso, os autores explicam que essa foi uma das formas encontradas pelos indígenas para se vingarem dos "constantes assaltos dos quilombolas a suas aldeias, de onde levavam suas mulheres" (REIS; GOMES, 1996, p. 19).

A imagem costumaz de que as fugas praticadas por pessoas escravizadas resultavam na formação de quilombos encontra nas passagens em direção à Bolívia um ponto de inflexão, que serve para analisar as movimentações internacionais. ${ }^{8}$ A opção dos fugitivos de migrarem para o território de outro Estado serve, por si só, para problematizar a associação entre as fugas e a reunião de quilombolas. Outro ponto a ser considerado refere-se à natureza dos próprios quilombos, que representariam nas palavras de

\footnotetext{
${ }^{8}$ Apesar de não intentar fazer um balanço da produção historiográfica sobre as movimentações internacionais de fuga das pessoas escravizadas, destaca-se a quantidade, a qualidade e a complexidade dos estudos relativos à fronteira sul do Império do Brasil, que congrega a maior parte dos trabalhos sobre o tema. No caso da fronteira oeste, alguns assuntos coincidem, em linhas gerais, com as abordagens propostas pelos pesquisadores especializados na fronteira sul. Entre os pontos que coincidem, ressalta-se a concessão de asilo territorial para os fugitivos pelos governantes dos territórios limítrofes ao Brasil; as negociações diplomáticas do Império do Brasil com o intuito de revalidar a propriedade escravizada, mesmo quando estivessem em domínio alheio; e, as tentativas das pessoas escravizadas de alargar suas possibilidades, seus espaços de autonomia ou modificar suas condições legais. Cita-se um apanhado dos trabalhos relativos à relação entre as linhas de fronteira e o trabalho escravizado: ARAÚJO, 2008; BORUCKI; CHAGAS; STALLA, 2009; CARATTI, 2008; FARINATTI; FLORES, 2009; GRINBERG, 2013; LIMA, 2010; PETIZ, 2006; ROMANI; MENEGAT; ARANHA, 2019; SECRETO, 2011; XAVIER, 2012.
} 
Carlos Magno Guimarães, uma espécie de "negação da ordem escravista" (GUIMARÃES, 1988, p. 45-53). No entanto, consideramos que as ilações entre as fugas, a formação de quilombos e as passagens internacionais ficariam mais bem contempladas a partir da premissa de que os quilombos não representavam uma negação da ordem, em função da possibilidade de haver uma convivência pacífica com os parâmetros legais e sociais que regulavam as sociedades circundantes, como no caso das complexas malhas de interesse e das relações comerciais que mantinham com diversos agentes sociais (VOLPATO, 1996, p. 231).

Embora não seja possível afirmar que novas escravizações de pessoas fugitivas fossem uma prática corrente no interior dos quilombos, há registros de que as mesmas se apresentavam como uma das muitas possibilidades associadas à fuga (GEARY, 2006, p. 321-22), acrescentando mais riscos às travessias. Os casos de reescravização de foragidos no interior dos quilombos ainda reforçam a lógica de perpetuação ou de possível convivência com regras, tradições e costumes existentes tanto no continente africano quanto nas sociedades do entorno. Acreditamos que as movimentações internacionais de fuga também não sirvam para indicar um rompimento com a chamada ordem escravista, sendo, antes, uma espécie de diálogo embasado na percepção dos escravizados em relação aos contextos políticos e sociais em que estavam inseridos. A ausência de uniformidade no trato com os escravizados/fugitivos pelas sociedades do entorno não passava despercebida por eles, que viam nos deslocamentos a chance de poderem reinventar suas próprias identidades, manejando as conjunturas internacionais a partir de alguma noção acerca da validação do princípio de territorialidade nos contatos entre os Estados-nação (FLORES, 2014, p. 90-4).

Em virtude das dificuldades apontadas, a fuga de longa distância provavelmente não figurava entre as primeiras opções para as pessoas escravizadas por se tratar de uma estratégia difícil de lograr êxito. ${ }^{9}$ Mesmo nos casos em

\footnotetext{
9 VOLPATO, 1987, p. 68-73; MEIRELES, 1989, p. 119-88. Ao pensar nas questões relativas às movimentações de fuga, evasões ou travessias, entendemos que o fenômeno deve ser particularizado de acordo com a região e o momento estudado. No caso da província de Mato Grosso, Luiza Volpato afirma que havia uma tradição de empreender as fugas para domínio alheio desde os tempos coloniais, chegando a adquirir algumas particularidades. A autora afirma ter havido na região fronteiriça o desenvolvimento de uma teia de interesses que envolvia indígenas, colonos, contrabandistas, pessoas escravizadas, militares, funcionários e até altos burocratas. O trabalho de Meireles coligiu informações acerca da existência de um intenso fluxo populacional na região, com as travessias sendo normalmente praticadas por colonos, escravizados, indígenas, soldados e contrabandistas, que, quando descobertos pelas
} 
que tais ações fossem bem-sucedidas, os fugitivos abandonavam não apenas as lógicas que orientavam o funcionamento da instituição no lado da fronteira em que residiam, mas também seus laços consanguíneos e de solidariedade, as paisagens cotidianas, suas relações parentais e as atividades rotineiras. Apesar dos rompimentos diários em relação às condições de vida conhecidas, dos perigos ao longo do caminho e da previsão legal de serem aplicadas severas punições contra os que fossem capturados durante as fugas (PETIZ, 2006, p. 89-94), os escravizados tomavam a decisão de fugir em função da combinação de inúmeros fatores. Além das motivações clássicas, que incluíam desde maus-tratos até a oferta insuficiente de alimentos, as evasões ainda ocorreram em função do possível esgotamento das margens de negociação dos escravizados junto aos seus proprietários (REIS; SILVA, 1989, p. 63-6). Ao analisar o perfil dos fugitivos, Marcia Amantino indicou a existência de subdivisões pautadas por gênero, etnia, aspectos culturais e locais de procedência dos mesmos, com destaque para as categorias de crioulo e de africano, que assumiram um destacado papel em seu estudo (AMANTINO, 2006, p. 61-9).

\section{A instrumentalização dos acontecimentos políticos e militares pelos fugitivos}

Os desdobramentos militares das disputas políticas entre os diversos segmentos da elite, assim como os conflitos sociais decorrentes das disparidades econômicas existentes no interior das províncias fomentaram a elevação do número de evasões. Em meio ao Período Regencial (1831-1840), um movimento político e social de cunho popular que ficou conhecido como Cabanagem, ocorrido na província do Grão-Pará entre 1835 e 1840, ilustra a forma como os enfrentamentos entre as elites políticas nacionais ou centrais e aquelas mais identificadas com os interesses regionais ou locais puderam ser instrumentalizadas pelas pessoas escravizadas. Em meio aos primeiros reveses nas lutas contra os cabanos, as tropas oficiais desferiram uma violenta repressão, promovendo milhares de assassinatos e concorrendo para

autoridades, procuravam asilo no campo oposto. A mobilidade espacial na região, assim como as dificuldades sentidas pelas autoridades de ambos os lados da fronteira de controlar as zonas limítrofes de forma rígida certamente acentuou as animosidades locais e regionais que reverberavam no relacionamento político das coroas ibéricas. O estímulo à prática de fuga, dado aos escravizados que habitavam o lado português pelas autoridades hispano-americanas que faziam promessas de liberdade, motivou os luso-brasileiros a tentar atrair os indígenas que residiam nos domínios hispano-americanos para o território luso-brasileiro. 
um sem-número de mortes (RICCI, 2007, p. 5-8). Trabalhos clássicos como os de Vicente Salles já demonstraram as variadas formas de engajamento das pessoas escravizadas nas lutas que se seguiram (SALLES, 1971, p. 269). No entanto, engana-se quem pensa que eles foram levados a reboque sem a formulação de bandeiras próprias. Salles, assim como Arthur Ramos (1956, p. 55), afirma que os negros escravizados incorporaram à luta reivindicações como a conquista da liberdade.

Em meio às disputas, os indígenas, os mestiços, os africanos livres, os libertos e os escravizados, assim como os proprietários de escravizados, os posseiros e os sitiantes, ajudaram a engrossar a fila dos descontentes, que vinha sendo puxada pela insatisfação da população livre e pobre em relação às precárias condições de vida. No caso das pessoas escravizadas, José Maia Bezerra Neto considera que as mesmas faziam "política por conta própria", uma vez que a bandeira da abolição não se constituía em ponto comum entre os cabanos. Nesse sentido, coube aos escravizados o papel de participar dos enfrentamentos, e, ao mesmo tempo, defender as próprias pautas, mesmo sofrendo a retaliação dos correligionários que eram contra a libertação dos escravizados (BEZERRA NETO, 2001, p. 76). Em meio aos episódios registrados pelo autor, constam fuzilamentos e perseguições a lideranças escravizadas defensoras da abolição.

Entre os pontos de aproximação dos estratos sociais menos favorecidos, destacamos o conhecido temor do alistamento militar compulsório, prática adotada com mais ênfase pelas autoridades em tempos de guerra (PEREGALLI, 1986, p. 29; IZECKSOHN, 2001, p. 89-95; HARRIS, 2017, p. 244-45). Havia ainda a ameaça de incorporação de índios, negros livres, libertos e mestiços ao Corpo de Trabalhadores, que, pela lei de 25 de abril de 1838, determinou a competência exclusiva das governantes para classificar tais indivíduos como uma ameaça à ordem e assim fazê-los servir em lavouras, na construção de obras públicas ou na prestação de serviços aos particulares mediante pagamento. Shirley Nogueira descreve uma estrutura de funcionamento militarizada, em que os trabalhadores eram alocados em companhias que se subdividiam em esquadras (NOGUEIRA, 2009, p. 265). Segundo a autora, havia comandantes responsáveis por não deixar os recrutados sem trabalho, assim como por adotar medidas severas contra quem acolhesse um escravizado em fuga e organizar expedições que visavam destruir os quilombos.

De muitas maneiras, especialmente por meio dos empreendimentos de fuga e das movimentações de deserção, essa parcela da população reagiu contra as arbitrariedades que vinham sendo praticadas ao se protegerem dos constantes recrutamentos e do controle mais rígido que passou a ser 
exercido pelas autoridades. ${ }^{10}$ Desse modo, uma das estratégias adotadas para assegurar a existência de espaços de autonomia foi a mobilidade de longa distância, possibilitando a identificação na correspondência das autoridades responsáveis pela manutenção da ordem na província de Mato Grosso, casos em que os fugitivos da província do Grão-Pará passaram a se fixar ao longo do curso dos rios Madeira e Mamoré, que franqueavam acesso à cidade de Mato Grosso. ${ }^{11}$ Por sua vez, os governantes mato-grossenses consideravam extremamente grave a possibilidade de que indivíduos dotados "com ânimos baixos e turbulentos" chegassem à Vila de Diamantino (localizada no atual estado de Mato Grosso - MT), por meio dos rios Tapajós e Arinos. ${ }^{12}$

No tocante às movimentações de fuga, Bezerra Neto afirmou que os contatos interétnicos eram comuns desde a época colonial, assim como a existência de uma complexa rede de intercâmbios de experiências e de informações que envolviam pessoas de variada condição social, incluindo até ideias abolicionistas (BEZERRA NETO, 2001, p. 80; 83; HARRIS, 2017, p. 227; SALLES, 1971, p. 267). Dessa forma, presumimos terem existido articulações que serviram como redes de apoio e de solidariedade entre as pessoas que se fixaram ao longo do curso dos rios e os fugitivos que estivessem apenas de passagem. Vicente Salles indica a existência de movimentações de fuga, em ambos os sentidos, entre a América portuguesa e a América francesa (Caiena) desde meados do século XVIII, sendo relativamente comuns os casos de pessoas escravizadas buscando asilo no outro lado (SALLES, 1971, p. 221-25). As correspondências trocadas entre os presidentes das províncias do Pará e de Mato Grosso indicam que houve a formação de quilombos nas regiões que passaram a ser ocupadas pelos fugitivos. Em um dos casos analisados, a chegada em Mato Grosso não representou o fim da jornada, com 14 prófugos optando por continuar a travessia em direção ao departamiento de Santa Cruz de la Sierra, localizado na porção oriental da República da Bolívia. ${ }^{13}$

A amplitude de tais movimentações foi múltipla e assumiu inúmeros significados, o que torna necessário considerar que as movimentações de fuga podem ser caracterizadas como "internas", relativas aos casos de evasão ocorridos dentro dos imprecisos limites territoriais das províncias de origem

\footnotetext{
${ }^{10}$ AHI 308/04/12 - Aviso [s/n. ${ }^{\circ}$, de 7/3/1836.

${ }^{11}$ Arquivo Nacional (AN) - (IJ' 918). Aviso n. ${ }^{\circ}$ 50, Cuiabá, 16 jun. 1835.

${ }^{12}$ AN - (IJ1 918). Aviso n. ${ }^{\circ}$ 50, de Cuiabá em 16/6/1835.

${ }^{13}$ AHI (211/01/18). Relatório da administração de Exaltación, de 3/8/1845, anexo ao ofício n. ${ }^{\circ}$ 11 , de $22 / 11 / 1845$.
} 
dos prófugos ou como "externas" ou internacionais. Em relação às movimentações de fuga ou às travessias, os avisos trocados entre os membros do ministério dos negócios estrangeiros do Brasil com os presidentes das províncias do Grão-Pará e de Mato Grosso demonstram que nem todos os escravizados que cruzaram as linhas de fronteira internacional eram, necessariamente, provenientes das províncias ou localidades mais próximas dos locais de refúgio (BANDEIRA, 1988, p. 123; SILVA, 2001, p. 158-59; 161-62). Desse modo, a instrumentalização das fugas aparece atrelada às brechas existentes em função do desconhecimento das autoridades em relação aos limites legais de suas atuações.

Por se tratarem de trajetórias construídas a partir de movimentos em que os fugitivos almejavam dissimular, esconder ou até mesmo apagar os próprios rastros, não parece razoável supor que os pesquisadores sejam capazes de recuperar com exatidão detalhes precisos acerca de suas travessias, tais como os locais exatos de suas partidas e de suas chegadas, seus nomes ou os de seus proprietários, bem como suas nacionalidades ou as circunstâncias que os haviam conduzido até aquele momento. Ainda assim, Vicente Salles destaca que antes de praticarem as evasões, os escravizados do Grão-Pará estavam envolvidos em atividades ligadas à indústria canavieira, à produção de arroz, fumo, cacau e na pecuária (SALLES, 1971, p. 264). Fora do domínio de seus senhores ou das autoridades constituídas em seus locais de origem, não houve a possibilidade de conhecer as culturas que passaram a produzir.

Em relação aos deslocamentos entre as províncias do Grão-Pará e de Mato Grosso, foram localizadas informações a respeito das providências tomadas pelo presidente da província de Mato Grosso, Antônio Pedro de Alencastro, para repelir a possível chegada dos "anarquistas do norte". O presidente reuniu uma tropa formada aparentemente apenas por cidadãos que residiam na província. A nova milícia - conhecida como Cívicos da Reserva -, foi dotada com o poder de polícia. Figurava entre as principais atribuições da tropa, o zelo pela tranquilidade pública em Cuiabá, que se daria ao não permitir a entrada de indivíduos classificados como "anarquistas desprezíveis". ${ }^{14}$ Apesar de não citar o movimento cabano textualmente, as referências acerca da índole dos indivíduos parecem suficientes para embasar o ponto de vista de que se tratavam de pessoas vindas do Grão-Pará. De todo modo, a formação da milícia no ano de 1835 parece indi-

$\overline{{ }^{14} \text { AN - (IJ1 918). Aviso n. }}{ }^{52}$, Cuiabá, 30 jun. 1835. 
car que os fugitivos vinham tentando penetrar - ou efetivamente adentravam - o território de Mato Grosso há algum tempo.

Essa certamente foi uma das variáveis consideradas pelo presidente para tomar a decisão de tentar barrar a entrada na província de "homens de cor", orientando as autoridades a não aceitarem a entrada de pessoas negras "que chegassem de fora do Brasil quando, no seu passaporte, não viesse declarada sua qualidade de ingênuo e, assim, abonada pelos cônsules e Encarregados de Negócios do local de origem". ${ }^{15}$ Destacamos a referência à precondição de entrada dos indivíduos "de cor", para reforçar a necessidade de eles não serem libertos. Em tais casos, a recomendação procurava afastar a possibilidade de retorno dos indivíduos possivelmente "libertos por asilo", ou seja, das pessoas escravizadas que haviam fugido do Brasil e que teriam adentrado o território de um Estado que tivesse adotado o princípio jurídico de $\underline{\text { solo livre. }}{ }^{16}$

Seguindo a leitura das fontes, o cuidado dos governantes da província de Mato Grosso sugere que as pessoas que pretendiam adentrar o Brasil seriam, na verdade, escravizadas fugitivas do solo brasileiro. ${ }^{17}$ Em meio às investigações, localizamos uma Ordem publicada sob orientação dos dirigentes bolivianos que faziam parte do governo central no ano de 1833, que tornava privativa a competência dos representantes centrais na emissão dos passaportes para as pessoas que pretendiam migrar ou emigrar. Desse modo, passava a ser proibida a expedição de tais documentos por representantes dos governos locais, como corregedores e governadores. ${ }^{18}$ Desconhecemos as razões que levaram os dirigentes centrais a tomar essa decisão, mas os pedidos feitos dois anos depois pelos asilados às autoridades locais revelam que as determinações não vinham sendo cumpridas.

A inexistência de convenções, atos, acordos, tratados etc., pactuados entre as chancelarias brasileira e boliviana tornou possível que pessoas acusadas de cometer crimes ou perseguidas por diferentes razões dentro dos limites de um Estado migrassem para viver sob a proteção do outro. A razão

${ }^{15}$ AN - (IJ1 918). Aviso n. ${ }^{\circ}$ 58, Cuiabá, 11 ago. 1835. [Grifo nosso].

${ }^{16}$ BERLIN, 2006, p. 283-84. O solo livre relaciona-se ao "princípio de liberdade", pelo qual uma pessoa escravizada conquistava o direito de viver em liberdade ao pisar o solo de um Estado que já tivesse adotado o expediente jurídico de abolir a vigência do regime de trabalho escravizado e proibido o tráfico e o comércio de novos escravizados; FONER, 2015, p. 144-50.

${ }^{17}$ AN - (IJ1 918). Aviso n. ${ }^{0}$ 58, Cuiabá, 11 ago. 1835.

${ }^{18}$ BOLÍVIA. Archivo Histórico de la Honorable Camara de Diputados. Coleccion Official de Leyes, Decretos, Ordenes, Resoluciones \&C, años 1833, 1834, y hasta la instalacion del Congreso de 1835. [La] Paz de Ayacucho: Imprenta del Colegio de Artes, 1835. p. 50. Orden de 27 de junio de 1833. 
para as travessias era a aplicação do princípio de territorialidade dos delitos, pelo qual um crime ou uma infração cometida no exterior não seria punida pelas autoridades locais. Na prática, as acusações eram invalidadas pelo fato de os atos infracionais ou criminais não retroagirem em contextos diversos daqueles em que tivessem sido praticados (CALDEIRA, 2017, p. 117-121). Em razão disso, os pedidos de devolução ou de extradição dos fugitivos asilados feitos pelas autoridades brasileiras muitas vezes não foram sequer respondidos pelos bolivianos. Ao escolherem fugir em direção ao território boliviano, alguns prófugos demonstravam ter alguma noção a respeito do quanto os conflitos de jurisdição e soberania poderiam favorecer seus interesses. ${ }^{19}$

No tocante às evasões em direção à Bolívia, os governantes daquele Estado sequer as consideravam como algo passível de punição desde 1830, quando foi publicado o primeiro Código Penal, que previa a libertação das pessoas escravizadas. ${ }^{20}$ Enquanto isso, as brasileiras procuravam revalidar o direito de propriedade dos senhores, mesmo nos casos em que as propriedades se encontrassem em domínio alheio. Para tanto, sugeriram a utilização do Direito das Gentes como parâmetro das negociações diplomáticas, mas a proposta se mostrou inviável em razão de estabelecer a reciprocidade dos atos internacionais como base de seu funcionamento. A inexistência de casos análogos remonta ao ano de 1826, momento em que os governantes bolivianos adotaram a primeira carta constitucional. A carta, apesar de ter proibido a introdução de novos escravizados e ter previsto a abolição da vigência do trabalho escravizado, serviu, ao mesmo tempo, para criar um regime jurídico misto ao legitimar a perpetuação da propriedade escravizada, nos casos em que as transações comerciais tivessem ocorrido antes da entrada em vigor da carta (JORDAN DE ALBARRACIN, 1978, p. 33-44).

De todo modo, os assuntos relativos à extradição, à repatriação ou à devolução das pessoas asiladas continuavam em aberto por inexistirem legislações em ambos os Estados que tipificassem os atos de fuga como ilícitos. Com relações diplomáticas marcadas por acusações mútuas, brasileiros e bolivianos viram os episódios de reclamação motivados pelo roubo do capital investido pelos proprietários brasileiros se avolumarem sem chegar a um acordo relativo à matéria. ${ }^{21}$ A promessa de restituição dos escraviza-

\footnotetext{
${ }^{19}$ AHI (211/01/18). Ofício n. ${ }^{\circ}$ 11, 22 nov. 1845.

${ }^{20}$ BOLÍVIA. Código Penal Boliviano. [La] Paz de Ayacucho: Imprenta del Colegio de Educandas, 1830.

${ }^{21}$ CALDEIRA, 2013, p. 38-40; 53-62. Questão presente desde 1829, quando foram iniciados os contatos diplomáticos entre brasileiros e bolivianos, os pedidos de extradição contribuíram
} 
dos asilados feita pelo vice-presidente da Bolívia foi um dos eventos que contribuíram para recrudescer as tensões entre os governos. Em 1836, José Miguel de Velasco Franco assumiu o compromisso de reforçar a fiscalização da polícia nas faixas de fronteira e extraditar os fugitivos que buscassem abrigo em solo boliviano. ${ }^{22}$ Para atender às novas orientações, o ministro das relações exteriores determinou que o prefeito de Santa Cruz de la Sierra passasse a considerar o cidadão brasileiro Mariano Ribeiro da Silva Apinagé na qualidade de comissário especial, dotado de autorização para identificar e enviar para o Brasil os escravizados que tivessem estabelecido domicílio naquelas paragens. ${ }^{23}$

O desenrolar das negociações demonstrou que os bolivianos passaram a impor algumas ressalvas com o intuito de resguardar o direito de propriedade dos cidadãos que tivessem adquirido escravizados foragidos até a data de publicação da circular. ${ }^{24}$ Outra condição para a execução da ordem foi o compromisso dos governantes brasileiros de que a restituição não implicaria na aplicação de castigos físicos. ${ }^{25}$ As fontes revelaram que uma comissão chefiada por Apinagé realmente atuou em solo boliviano, apresentando uma lista às autoridades departamentais que continha os nomes dos cativos asilados, seus locais de procedência e os nomes de seus respectivos proprietários. ${ }^{26}$ A lista ainda continha subdivisões entre os fugitivos que teriam se dirigido para Santa Cruz de la Sierra e os que haviam seguido em direção a Chiquitos.

Um documento revela a sugestão do então presidente da província de Mato Grosso José Antônio Pimenta Bueno (1803-1878) para que os escravizados que se encontrassem na condição de refugiados fossem apreendidos e "aplicados a trabalhos públicos n'essa Capital [Santa Cruz] e em Chiqui-

\footnotetext{
para o aumento da quantidade de vezes em que ambas as chancelarias negociaram acordos e, nas duas décadas que se seguiram, a pauta foi intensificada ora em função das reclamações dos proprietários brasileiros e ora em decorrência de uma necessidade pontual de cada governo. Apesar de o tratamento conferido pelos governantes ter variado ao longo do tempo, pode-se inferir, a partir de uma leitura das fontes diplomáticas depositadas no arquivo do Itamaraty, que a década de 1840 foi a mais emblemática, com a chancelaria brasileira passando a acusar os governantes bolivianos de roubar o capital dos súditos brasileiros no momento em que concediam asilo territorial para os escravizados foragidos que chegassem ao território boliviano.

${ }^{22}$ AHI (410/01/05). Nota n. ${ }^{\circ}$ 5, 18 jan. 1837.

${ }^{23}$ AHI (410/01/05). Nota n. ${ }^{\circ}$ 6, 11 fev. 1837.

${ }^{24}$ AHI (410/01/05). Circular [s/n. ${ }^{\circ}$, anexa sob n. ${ }^{0}$ 5, à nota n. ${ }^{0}$ 5, 18 jan. 1837.

${ }^{25}$ AHI (410/01/05). Nota n. ${ }^{\circ}$ 7, 12 fev. 1837.

${ }^{26}$ Archivo Histórico da Universidad Autónoma Gabriel René Moreno (UAGRM) - F/MMC19-L2 - Carpeta 19-Legajo 2 - Carta de 6 mar. 1837.
} 
tos por tempo conveniente para indenização das despesas ocasionadas por aquela diligencia, depois do que houvessem de ser enviados à Fronteira". ${ }^{27}$ Em outra passagem, a autoridade brasileira recomendou que os cativos apreendidos fossem conservados na prisão para impossibilitar novas fugas. Em carta ao prefeito de Santa Cruz, o presidente assumiu a responsabilidade de pagar indenizações que compensariam as despesas feitas durante a apreensão, conservação e escolta até a fronteira.

Além disso, Pimenta Bueno indicou a necessidade de os governantes bolivianos reunirem tropas capazes de executar a tarefa de entregá-los às rondas de Cazalvasco. As cartas trocadas entre Apinagé e o representante da diplomacia brasileira na Bolívia, Duarte da Ponte Ribeiro (1795-1878), revelam que o comissário estava autorizado a fazer os gastos que fossem necessários na tentativa de reaver os escravizados. Ponte Ribeiro também orientou o comissário a repassar aos proprietários os custos da devolução.28 Em outra carta, Ribeiro aprovou a iniciativa de Apinagé de oferecer a prestação de serviços pelo período de três meses, em decorrência da concessão da extradição dos asilados. ${ }^{29}$

Foram localizados documentos que mencionam a chegada em Santa Cruz de quatro cativos oriundos do Brasil, em 1833, ou seja, antes de o vice-presidente assumir o compromisso de restituir os escravizados. Consta que os foragidos se chamavam Quintino, Bento, Eva e Feliciana e que eles eram propriedades do brasileiro Antonio Rodrigues da Costa. A fonte indica que a prefeitura havia deixado a cargo da intendência de polícia a tarefa de permitir que tais indivíduos trabalhassem para cidadãos bolivianos honrados a fim de conseguir os meios necessários de subsistência. As informações indicam que Bento havia morrido depois de sofrer com uma peste mortífera e que os demais continuavam vivendo na Bolívia. Consta ainda que o prefeito de Santa Cruz acatou as orientações de seu governo ao tomar as necessárias providências para entregar os refugiados a Apinagé. ${ }^{30}$ Aproximadamente um mês depois, uma carta deu ciência ao ministro de que os fugitivos tinham sido entregues. ${ }^{31}$ Ao que tudo indica, houve ao menos um caso de devolução de escravizados asilados.

\footnotetext{
${ }^{27}$ UAGRM - F/MMC19-L2 - Carpeta 19-Legajo 2 - Carta de 11 maio 1838.

${ }^{28}$ AHI 454-4-17 - Carta n. ${ }^{\circ}$ 2, 13 fev. 1837.

${ }^{29}$ AHI 454-4-17 - Carta n. ${ }^{\circ}$ 2, 13 mar. 1837.

${ }^{30}$ Archivo y Biblioteca Nacionaldes de Bolivia (ABNB). MI-46-31 - Correspondência n. ${ }^{0}$ 3, 12 out. 1833.

${ }^{31}$ ABNB. MI-69-21 - Correspondência n. ${ }^{0}$ 106, de 9/11. Na fonte, não localizamos o nome dos remetentes, destinatários ou ano de envio.
} 
O ambiente de cooperação foi modificado por um episódio de fuga ocorrido em 1837, quando 17 presos da cadeia pública de Cuiabá fugiram em direção ao território boliviano. ${ }^{32} \mathrm{O}$ acolhimento dos fugitivos motivou o envio de sucessivas notas de protesto dos governantes brasileiros. Em resposta, as autoridades bolivianas não negaram a entrada dos fugitivos, mas exigiram a apresentação de provas contra os acusados. ${ }^{33}$ Para deixar de atender aos pedidos de extradição, a chancelaria boliviana voltou a defender a inexistência de atos internacionais que tornassem obrigatória a devolução dos asilados. A mudança de postura não surpreendeu Ponte Ribeiro, que interceptou uma correspondência do ministro do interior da Bolívia endereçada às autoridades de Santa Cruz de la Sierra. O ministro orientou o prefeito a levar adiante a repatriação dos 17 asilados, ao passo que, ao mesmo tempo, recomendou que as autoridades locais "los mande internar para Yungas, o otro lugar distante, cuando no van darnos disgustos" ainda maiores. ${ }^{34}$

A mudança de orientação dos governantes bolivianos se materializou na publicação de um decreto em janeiro de 1838, que afastou a possibilidade de repatriação dos fugitivos. ${ }^{35}$ As notas trocadas entre o representante brasileiro João da Costa Rego Monteiro e o ministro das relações exteriores da Bolívia, em 1838, demonstram que o ministro passou a embasar as negativas de devolução pelo texto do novo decreto, que, em suas palavras, seria uma "consequência necessária das leis bolivianas". ${ }^{36}$ Ao perceber que os pedidos de devolução não seriam cumpridos, Rego Monteiro alertou o ministério dos negócios estrangeiros acerca da existência de matérias legais que tornariam inconstitucional a devolução dos asilados. A elevação do tom dos protestos brasileiros indica que a questão continuou em aberto e adquiriu novos contornos.

Em meados de 1845, outro episódio envolvendo a travessia de pessoas do Brasil para a Bolívia mobilizou a atenção das autoridades. Em ofício endereçado ao ministro dos negócios estrangeiros, Rego Monteiro informou

\footnotetext{
${ }^{32}$ Arquivo Público Estadual de Mato Grosso (APMT). Estante 5 - maço 39 - Correspondência, 8 mar. 1837.

${ }^{33}$ AHI (211/01/18). Nota n. ${ }^{\circ}$ 20, 26 dez. 1838.

${ }^{34}$ Ministerio de Relaciones Exteriores de Bolivia - (MRE Bo) - LE - 3-R-5 - Documento, 28 out. 1837.

35 AHI (410/01/05). Nota n 21, 27 dez. 1838.

${ }^{36} \mathrm{ABNB}-\mathrm{M} 474-\mathrm{II}$ - Breve exposicion de las razones que tuvieron los que suscriben este folleto como diputados a la Asamblea Nacional de 1868, para dar su voto de aprobacion en favor del tratado de amistad, límites, navegacion, comercio y extradicion, ajustado entre los plenipotenciários de Bolivia y del Brasil en la ciudad de La Paz en 27 de Marzo de 1867. Cochabamba: Imprenta Gutierrez, 1871. p. 38.
} 
ter recebido do brasileiro Apinagé, a informação de que 27 pessoas negras fugitivas das províncias do Pará e de Mato Grosso haviam chegado em Santa Cruz de la Sierra. Desde o início, os governantes brasileiros procuraram não acusar os asilados de praticar crimes políticos, pois havia uma tradição na prática entre os Estados da região de conceder refúgio aos indivíduos que estivessem envolvidos em comoções políticas. Com o intuito de elevar as chances de devolução, os dirigentes brasileiros preferiram acusá-los de praticar crimes comuns. A solução encontrada foi equiparar a fuga ao roubo do capital investido pelos proprietários no ato de compra. Esse seria apenas mais um caso de fuga internacional, se não figurassem entre os asilados alguns indivíduos considerados desertores. O ministro boliviano recomendou que Rego Monteiro enviasse uma nota em que constassem tanto os nomes dos desertores quanto os seus locais de procedência. A intenção, segundo o ministro, seria facilitar o trabalho de averiguação das autoridades policiais.

A troca de correspondências revelou que o ministro boliviano havia se comprometido a restituir os asilados, no caso de a investigação conduzida pelo prefeito do Beni indicar a presença de desertores entre os prófugos. ${ }^{37} \mathrm{No}$ entanto, a condução do assunto sofreu uma alteração significativa no momento em que o ministro passou a exigir que o governo brasileiro validasse o Tratado de Santo Ildefonso (1777), por julgar que a Bolívia teria maiores compensações territoriais. Os dirigentes bolivianos aproveitaram a ocasião para pleitear o direito de navegar livremente os rios internacionais que estavam sob jurisdição parcial do Império do Brasil, que tornaria possível o acesso ao oceano Atlântico. Motivados pelo pedido de extradição feito pelos brasileiros, os governantes bolivianos abriram uma linha de investigação que desejava, em tese, conhecer as razões que teriam motivado a travessia. Os depoimentos dos asilados, se tomados como verdadeiros, são um raro registro da versão dos "escravizados" para os riscos e as expectativas que cercavam os casos de fuga internacional.

Ao reunir as informações disponíveis, Rego Monteiro identificou 14 dos 27 fugitivos como desertores das tropas brasileiras. A identificação dos fugitivos como desertores criou uma situação imprevista pela legislação boliviana, que somente permitia o aceite de civis e não de militares. Segundo consta na publicação do decreto de 26 de julho de 1845, o ministro Frias determinou que o prefeito do Beni averiguasse os locais de procedência dos

37 MRE Bolívia - LIM-1-180 - Carta, 27 ago. 1845. 
indivíduos asilados, os motivos da fuga, as rotas percorridas, os nomes de seus patrões e os meios de transporte utilizados em suas movimentações. ${ }^{38}$ As investigações concluíram que 14 fugitivos teriam saído das localidades de Rio Negro e de Mura, ambas situadas na província do Grão-Pará.

Em seus depoimentos, os asilados declararam possuir a condição legal de escravizados, o que poderia fazer parte da estratégia de burlar a possibilidade de repatriação e conseguir a anuência dos governantes bolivianos em relação às suas permanências. Ao serem questionados a respeito das motivações para realizarem a travessia internacional, os fugitivos declararam ter a intenção de se libertar da tirania do chamado "partido legal", que lutava contra o partido oposto, denominado "cabano". Os relatos apontam que as autoridades da província do Grão-Pará teriam prometido conceder aos escravizados que se engajassem na guerra contra os cabanos um período "de descanso [do cativeiro] para que pudessem trabalhar, e, assim, juntar o pecúlio necessário para se libertarem da escravidão para com os seus senhores". ${ }^{39}$ Desse modo, acreditamos que os depoimentos dos fugitivos ajudam a complexificar a compreensão a respeito dos possíveis arranjos entre proprietários, governantes e escravizados, contribuindo para o surgimento de contradições como a da liberdade temporária.

Uma pista acerca do funcionamento dessa condição transitória é fornecida pela documentação, que indica que o tempo de descanso da escravidão seria equivalente ao período em que as pessoas escravizadas tivessem se engajado na luta contra os cabanos. ${ }^{40} \mathrm{O}$ avanço das investigações demonstrou que o partido legal não respeitou a promessa de concessão de liberdade temporária feita aos escravizados, impondo a volta dos castigos físicos e das prisões. No momento em que os vitoriosos passaram a cobrar o cumprimento do acordo, pelo qual teriam direito a seis anos de descanso, as autoridades decidiram calar a voz dos descontentes ao entregá-los aos antigos proprietários.

Apesar de terem lutado e vencido a guerra, a precariedade de suas condições legais é absoluta. No entanto, a hipótese de essa versão do ocorrido ter sido pensada pelos asilados com o objetivo de angariar as simpatias dos governantes bolivianos não pode ser descartada, uma vez que eles se esfor-

\footnotetext{
38 AHI (211/01/18). Cópia do decreto, anexa ao ofício n. ${ }^{\circ} 10,5$ out. 1845.

39 AHI (211/01/18). Cópia do decreto, anexa ao ofício n. ${ }^{\circ} 10,5$ out. 1845.

${ }^{40}$ AHI (211/01/18). Relatório da administração de Exaltación, de 3/8/1845, anexo ao ofício n. ${ }^{\circ}$ 11, 22 nov. 1845. Cumpre observar que as informações prestadas no âmbito de um processo que poderia trazer consequências diretas para a vida dos depoentes devem ser relativizadas e mais bem investigadas a fim de se verificar inclusive a existência dessa condição transitória.
} 
çavam para serem considerados dignos do asilo concedido. Em razão disso, a sua preocupação em construir uma imagem positiva junto às autoridades fica evidente ao reforçarem a imagem de fidelidade e obediência no cumprimento das ordens recebidas durante o período em que estiveram a serviço das tropas legais. Os asilados ainda afirmaram terem zelado pela correta observância das leis e das propriedades de seus proprietários e do Império do Brasil, quando ainda viviam em seus locais de origem. O discurso uniforme adotado pelos fugitivos parece indicar que eles sabiam da importância que o respeito pela ordem teria para permanecerem em solo boliviano.

De acordo com os depoentes, os riscos assumidos durante as travessias eram compensados pela possibilidade de se libertarem do cativeiro. Nos relatos dos fugitivos, a República da Bolívia aparece como sendo o local escolhido por seus corações para morar e obter a tão sonhada paz. ${ }^{41} \mathrm{O}$ plano de evasão também figura como um ponto em comum na fala dos asilados, que teriam tido notícias vindas do Rio de Janeiro de que na Bolívia os escravizados brasileiros contavam com o amparo das leis no momento em que pisassem no seu território. Em relação às rotas de fuga e aos meios empregados na sua execução, os asilados afirmaram ter seguido as margens do rio Beni, que confluía com o rio Pará. Em quatro meses, os fugitivos teriam realizado a travessia a pé, sem o auxílio de canoas. No tocante aos meios de subsistência, os depoentes declararam ter pescado e coletado as frutas que abundavam na região. Por último, afirmaram que se o intento de fuga não fosse bem-sucedido, adotariam a estratégia de recorrer à proteção de seus senhores por serem considerados propriedades dentro do território brasileiro.

O resultado das investigações concluiu que a conduta irrepreensível dos prófugos, considerados pessoas trabalhadoras e industriosas no povoado de Cayuvaba, sustentava a concessão de asilo em caráter definitivo. Na opinião do investigador boliviano, a permanência deles estaria de acordo com a aplicação dos princípios de filantropia e hospitalidade, visto que os interrogados eram pessoas "com cujas qualidades tem merecido as simpatias de todos". As palavras de Rafael de la Borda demonstram a importância da reputação dos investigados em sua decisão, pois "los empleados de este cantón y sus honrados vecinos han favorecido a estos desgraciados, prestándolos todos a porfía los primeros recursos y auxilios más necesarios para la

\footnotetext{
${ }^{41}$ AHI (211/01/18). Relatório da administração de Exaltación, de 3/8/1845, anexo ao ofício n. ${ }^{\circ}$ 11 , de $22 / 11 / 1845$.
} 
vida". ${ }^{22}$ As investigações duraram pouco mais de três meses e um incidente fronteiriço ocorrido em uma das divisas parece ter influenciado o parecer final do governo boliviano.

O episódio envolveu o boliviano Miguel Bernardino Vargas, que saiu do Beni com a intenção de comerciar em Cuiabá, utilizando a via de Itenés. Consta que Vargas foi proibido de entrar em solo brasileiro por ordem do Comandante do Quartel do Forte do Príncipe, que, em seu passaporte, deu ordens expressas para o boliviano regressar. Embora não haja condições de afirmar se a tentativa de Vargas fez parte de algum tipo de estratégia do governo boliviano para obstar a devolução dos fugitivos asilados, ${ }^{43}$ a negativa do comandante repercutiu nas negociações diplomáticas em curso e, possivelmente, influenciou a tomada de decisão dos dirigentes bolivianos, que, ao final, preferiram considerar os asilados na condição de escravizados e não como desertores, como reivindicava os governantes brasileiros. ${ }^{44}$ Depois de concluída a investigação, esses asilados não foram mais mencionados pela documentação, deixando as condições de vida e seu status legal em suspenso. Afinal, terão sido reescravizados ou reconhecidos como cidadãos pelos governantes bolivianos?

\section{Considerações finais}

Ao criar um personagem que imaginava ser possível destruir a alma e a vontade dos fugitivos, Isabel Allende atentou para a constância de tais movimentações no interior dos mundos do cativeiro, algo que, na esfera internacional, a historiografia brasileira têm se dedicado a demonstrar. Por muito tempo, os estudiosos de temas que envolviam as categorias de escravidão e de liberdade partiam da certeza de que ambas seriam antagônicas, praticamente estanques, dentro dos intervalos de tempo e de lugar em que vigoraram. Aos sujeitos históricos considerados inaptos para dialogar com contextos próprios de uma vida de exploração ou com conjunturas marcadas pelas poucas oportunidades de mudança da condição legal, restava o imobilismo. A percepção quanto à existência de espaços de autonomia, mesmo em regimes de trabalho marcados por relações assimétricas, fez que

\footnotetext{
${ }^{42}$ AHI (410/01/05). Nota n. ${ }^{\circ} 12,8$ nov. 1845.

${ }^{43}$ AHI (410/01/05). Nota n. ${ }^{\circ} 10,2$ out. 1845.

${ }^{44}$ AHI (211/01/18). Ofício n. ${ }^{\circ} 11,22$ nov. 1845.
} 
esses mesmos estudiosos percebessem a presença de um mundo próprio, marcado pela criatividade dos subjugados.

Neste trabalho, buscamos trazer uma discussão a respeito das possibilidades que as pessoas escravizadas experimentavam ao fugir, por entender que as mesmas não só interagiam com os desafios que lhes eram impostos, mas também agiam e se articulavam a partir de lógicas que escaparam do controle das autoridades, dos proprietários ou do mundo ou submundo das leis, ordens, regulamentos etc., existentes. Não se trata, porém, de associar as movimentações de fuga à aquisição da liberdade ou à formação de quilombos, mas, sim, de perceber os impactos que as evasões tiveram nas sociedades envolvidas e nas relações diplomáticas dos Estados. Da mesma forma, o caráter transitório e fugidio das fugas em si não permite afirmar que as fugas tencionavam negar a ordem social vigente. $\mathrm{O}$ caso dos asilados do Rio Negro e de Mura ilustra a maneira como esse maior espaço de autonomia criava "liberdades" precarizadas que constantemente poderiam ser ameaçadas pela repressão dos agentes do Estado ou pelas ações de particulares em ambos os lados da fronteira. ${ }^{45}$

No caso dos estudos sobre o fenômeno das movimentações de evasão ou das travessias, os documentos revelam uma dificuldade a mais, a imprecisão dos locais de parada. O caráter transitório das fugas, associado à imprevisibilidade em relação ao seu alcance viabilizam a composição de um mosaico fluido de ações e reações difíceis de serem mapeadas. As alianças e as articulações entre os escravizados fugitivos e destes com os indígenas e os demais indivíduos marginalizados (desertores, devedores e fugitivos da lei) também merecem ser mais bem estudadas (SILVA, 2003, p. 285-88). No caso de boa parte dos quilombos, por não haver uma estratégia de defesa do território - nos casos em que chegavam a ser formados -, também não existiu o emprego de expedições contra os aquilombados, o que reduz as chances de se conhecer as trajetórias dos fugitivos, bem como suas estratégias de sobrevivência.

O estudo dos casos de fuga das pessoas escravizadas para fora do território brasileiro torna imprescindível conhecer minimamente a história do local para o qual os prófugos se dirigiram para que o pesquisador possa aventar perspectivas e possibilidades. Em tais casos, as análises advindas das dinâmicas marcadas pela circulação de ideias, de pessoas, de técnicas

\footnotetext{
${ }^{45}$ Entre as possibilidades de estudo acerca da precarização das formas de liberdade e de suas vivências em espaços urbanos, consultar: CHALHOUB, 2012.
} 
etc., estariam de acordo com os deslocamentos dos agentes pelos territórios. Ao exemplificar tais dinâmicas, Peter Linebaugh utilizou a metáfora do bumerangue para ilustrar a existência de movimentos de interação, circulação, comércio e sobrevivência (LINEBAUGH, 1988, p. 228-31). As fugas em direção ao além-fronteiras são um bom exemplo de apreensão e reinterpretação das realidades que se abriam aos escravizados.

Se, como afirma Barbara Fields, a liberdade seria algo em constante movimento (FIELDS, 1985, p. 193), estudar as movimentações de fuga possibilitam ao pesquisador borrar processos históricos, que, em tese, seriam delimitados pelas tradicionais barreiras políticas entre os Estados. Assim como Fields e Neil Roberts, procuramos destacar a importância da agência dos escravizados na alteração das circunstâncias sociais e nas relações políticas que condicionavam suas existências. Do mesmo modo, também parece acertada a afirmação feita por ambos de que a conquista da liberdade pessoal e a existência do trabalho escravizado não decorreriam de uma relação inerte. Entre os pontos de aproximação com a obra de Roberts, ressaltamos o apontamento feito em relação à necessidade de serem desenvolvidas "concepções crioulas de escravidão e liberdade" (ROBERTS, 2015, p. 103-16). No entanto, mesmo destacando a relevância das fugas, não foi possível concluir que a conquista da liberdade residiria em tais movimentações.

Pelo caráter do objeto e pelo tipo de registro que consta nas fontes, uma parte das reflexões permanecerá em aberto. Entre as questões que gostaríamos aprofundar, constam, por exemplo, onde começava a autonomia dos fugitivos ou terminava suas escravizações. Teriam conseguido viver como pessoas livres? Obtido a cidadania, de acordo com as previsões legais? Mesmo nos casos em que os escravizados conseguiram viver como livres, parece impossível dar a conhecer os possíveis significados da liberdade para os libertos, considerando-se a variação das sensibilidades envolvidas. Se, para os libertos estudados por Eric Foner nos Estados Unidos da América, a liberdade poderia significar a possibilidade de usarem roupas coloridas (FONER, 1988, p. 12-4), para os fugitivos do Grão-Pará ou de Mato Grosso pode ter sido a criação de espaços de autonomia que os deixavam fora do alcance das autoridades brasileiras. Os limbos jurídicos em que os fugitivos passavam a viver representam a falta de correlação entre a vida em liberdade e os mundos do trabalho escravizado.

Nos casos de evasão em direção ao território da Bolívia, não foram localizadas reivindicações direcionadas aos proprietários, fazendo aparentar, em um primeiro momento, que tais movimentações seriam dotadas de um caráter definitivo. No entanto, as tentativas de retorno ao território brasileiro 
das pessoas possivelmente libertas por asilo durante a década de 1830 ajudaram a desfazer a impressão inicial. Além dos riscos inerentes às fugas, houve ainda a necessidade de os prófugos se adaptarem às novas línguas, costumes e tradições, que poderiam facilitar ou não suas adaptações nos locais em que tivessem passado a residir. De todo modo, a permeabilidade das linhas de fronteira, no que tange às possibilidades de os fugitivos conquistarem mais autonomia ou de modificarem suas condições legais, deve ser considerado com cautela. O risco de ocorrerem reescravizações e engajamentos militares compulsórios se fizeram presentes em ambos os lados da fronteira, não assegurando aos fugitivos que suas movimentações resultariam na aquisição da liberdade. Esta última, quando ocorreu, foi apenas uma dentre tantas outras possibilidades (GRINBERG, 2016, 259-90).

\section{FONTES PRIMÁRIAS \\ Arquivo Nacional, Rio de Janeiro/Brasil}

AN - (IJ1 918). Aviso n 50, Cuiabá em 16/6/1835.

AN - (IJ1 918). Aviso n 52, Cuiabá em 30/6/1835.

AN - (IJ1 918). Aviso n 58, Cuiabá em 11/8/1835.

\section{Arquivo Histórico do Itamaraty, Rio de Janeiro/Brasil}

AHI 308/02/08 - Correspondência anexa ao ofício nº 5, de Cuiabá em 14/9/1835.

AHI 308/04/12 - Aviso s/n, de 7/3/1836.

AHI (410/01/05). Nota $n^{\circ} 5$, de 18/1/1837.

AHI (410/01/05). Nota $n^{\circ}$ 6, de 11/2/1837.

AHI (410/01/05). Nota $n^{\circ} 7$, de 12/2/1837.

AHI 454-4-17 - Carta no 2, de 13/2/1837.

AHI 454-4-17 - Carta no 2, de 13/3/1837.

AHI (211/01/18). Nota $n^{0} 20$, de 26/12/1838.

AHI (410/01/05). Nota $n^{\circ} 21$, de 27/12/1838.

AHI (211/01/18). Relatório da administração de Exaltación, de 3/8/1845, anexo ao ofício $\mathrm{n}^{\circ} 11$, de 22/11/1845.

AHI (410/01/05). Nota $n^{0} 10$, de 2/10/1845.

AHI (211/01/18). Cópia do decreto, anexa ao ofício nº 10, de 5/10/1845.

AHI (410/01/05). Nota $n^{0} 12$, de 8/11/1845.

AHI (211/01/18). Ofício nº 11, de 22/11/1845.

\section{Arquivo Público Estadual de Mato Grosso (APMT), Cuiabá/Brasil}

APMT - Estante 5 - maço 39 - Correspondência de 8/3/1837. 


\section{Archivo Histórico da Universidad Autónoma Gabriel René Moreno, Santa Cruz de la Sierra/Bolivia}

UAGRM - F/MMC19-L2 - Carpeta 19-Legajo 2 - Carta de 6/3/1837.

UAGRM - F/MMC19-L2 - Carpeta 19-Legajo 2 - Carta de 11/5/1838.

\section{Archivo y Biblioteca Nacional de Bolivia, Sucre/Bolívia}

BOLÍVIA. Código Penal Boliviano. [La] Paz de Ayacucho: Imprenta del Colegio de Educandas, 1830.

BOLÍVIA. Constituição Política da República da Bolívia, de 19/11/1826.

ABNB. MI-46-31 - Correspondência nº 3, de 12/10/1833.

ABNB. MI-69-21 - Correspondência no 106, de 9/11.

ABNB - M474-II - Breve exposicion de las razones que tuvieron los que suscriben este folleto como diputados a la Asamblea Nacional de 1868, para dar su voto de aprobacion en favor del tratado de amistad, límites, navegacion, comercio y extradicion, ajustado entre los plenipotenciários de Bolivia y del Brasil en la ciudad de La Paz en 27 de Marzo de 1867. Cochabamba: Imprenta Gutierrez, 1871.

\section{Ministerio de Relaciones Exteriores de Bolivia, La Paz/Bolívia}

MRE Bo - LE - 3-R-5 - Documento de 28/10/1837.

MRE Bolívia - LIM-1-180 - Carta de 27/8/1845.

\section{Archivo Histórico de la Honorable Camara de Diputados, La Paz/Bolívia}

Archivo Histórico de la Honorable Camara de Diputados. Coleccion Official de Leyes, Decretos, Ordenes, Resoluciones $\mathcal{E}$ c, años 1833, 1834, y hasta la instalacion del Congreso de 1835. [La] Paz de Ayacucho: Imprenta del Colegio de Artes, 1835. p. 50. Orden de 27 de junio de 1833.

\section{Referências Bibliográficas}

ALLENDE, Isabel. A ilha sob o mar. Rio de Janeiro: Bertrand Brasil, 2011.

AMANTINO, Márcia. Os escravos fugitivos em Minas Gerais e os anúncios do jornal "O Universal" - 1825 a 1832. Locus: revista de história, Juiz de Fora, v. 12, n. ${ }^{\circ}$ 2, 2006, p. 61-69. Disponível em: <http://www.ufjf.br/locus/files/2010/02/33. pdf>. Acesso em: 25/05/2019.

ARAÚJO, Thiago Leitão de. Escravidão, fronteira e liberdade: políticas de domínio, trabalho e luta em um contexto produtivo agropecuário (vila da Cruz Alta, província do Rio Grande de São Pedro, 1834-1884). Dissertação (Mestrado em História) - PPGH, UFRGS, Porto Alegre, 2008.

BANDEIRA, Maria de Lourdes. Território negro em espaço de branco. São Paulo: Editora Brasiliense, 1988. 
BERLIN, Ira. Gerações de cativeiro: uma história da escravidão nos Estados Unidos. Rio de Janeiro: Record, 2006.

BEZERRA NETO, José Maia. Ousados e insubordinados: protesto e fugas de escravos na província do Grão-Pará (1840-1860). Topoi: Revista de História, Rio de Janeiro, v. 2, 2001, p. 76. DOI disponível em: < http://dx.doi.org/10.1590/ 2237-101X002002003>. Acesso em: 21/06/2007.

BORUCKI, Alex; CHAGAS, Karla; STALLA, Natalia. Esclavitud y trabajo: un estudio sobre los afrodescendientes en la frontera uruguaya. Montevidéu: Mastergraf, 2009.

CALDEIRA, Newman Di Carlo. Cativos asilados: direito de propriedade, liberdade e condição legal nas relações diplomáticas do Império do Brasil com a República da Bolívia, 1829-1867. In: GOMES, Flávio dos Santos; SECRETO, María Verónica. (Orgs.). Territórios ao sul: escravidão, escritas e fronteiras coloniais e pós-coloniais na América. Rio de Janeiro: 7 Letras, 2017.

CALDEIRA, Newman Di Carlo. Os casos de fuga internacional de escravos e a atuação da Chancelaria brasileira: as negociações com a República da Bolívia entre 1829 e 1870. Revista Eletrônica da ANPHLAC, ISSN 1679-1061, n. ${ }^{0}$ 15, p. 3778, jul. dez. 2013.

CARATTI, Jônatas. Os extraditados: a ação do consulado uruguaio na libertação dos negros orientais escravizados ilegalmente na província de São Pedro do Rio Grande do Sul (1850 e 1860). Revista Mouseion, v. 2, n. ${ }^{\circ}$ 3, jan.-jun. 2008.

CHALHOUB, Sidney. A força da escravidão: ilegalidade e costume no Brasil oitocentista. São Paulo: Companhia das Letras, 2012.

DÍAZ VILLAMIL, Antonio. Historia General de Bolivia. La Paz: Editorial Popular, [19--].

FARINATTI, Luís; FLORES, Mariana Thompson. Fronteira manejada: apontamentos para uma história social da fronteira meridional do Brasil (século XIX). In: HEINZ, Flávio (org.). Experiências nacionais, temas transversais: subsídios para uma história comparada da América Latina. São Leopoldo: Oikos, 2009.

FIELDS, Barbara. Slavery and freedom on the middle ground: Maryland during the nineteenth century. New Haven: Yale University Press, 1985.

FONER, Eric. Gateway to Freedom: The Hidden History of the Underground Railroad. New York: W. W. Norton $\mathcal{E}$ Company, 2015.

FONER, Eric. O significado da liberdade. Revista Brasileira de História, São Paulo, v. 8, n. ${ }^{\circ} 16$, p. 9-36, mar., ago. 1988.

FLORENTINO, Manolo (org.). Tráfico, cativeiro e liberdade (Rio de Janeiro, séculos XVII-XIX). Rio de Janeiro: Civilização Brasileira, 2005.

FLORES, Mariana Flores da Cunha Thompson. Crimes de fronteira: a criminalidade na fronteira meridional do Brasil (1845-1889) [recurso eletrônico]. Porto Alegre: EDIPUCRS, 2014.

GEARY, Dick. Europa e o protesto escravo nas Américas, 1780-1850. In: LIBBY, Douglas Cole; FURTADO, Júnia Ferreira (orgs.). Trabalho livre, trabalho escravo: Brasil e Europa, séculos XVII e XIX. São Paulo: Annablume, 2006.

GRINBERG, Keila. The Two Enslavements of Rufina: Slavery and International Relations on the Southern Border of Nineteenth-Century Brazil. Hispanic American Historical Review, 96 (2): 259-290, maio 2016. DOI disponível em: < https:// 
doi.org/10.1215/00182168-3484173>. Disponível em:<https://read.dukeupress. edu/hahr/article-abstract/96/2/259/36590/The-Two-Enslavements-of-Rufina-Slavery-and $>$. Acesso em: 15 maio 2020.

GRINBERG, Keila. As fronteiras da escravidão e da liberdade no sul da América. Rio de Janeiro: 7 Letras, 2013.

GUIMARÃES, Carlos Magno. Uma negação da ordem escravista: quilombos em Minas Gerais no século XVIII. São Paulo: Ícone, 1988.

HARRIS, Mark. Rebelião na Amazônia: Cabanagem, raça e cultura popular no Norte do Brasil, 1798-1840. Campinas, São Paulo: Unicamp, 2017.

IZECKSOHN, Vitor. Resistência ao recrutamento para o Exército durante as guerras Civil e do Paraguai: Brasil e Estados Unidos na década de 1860. Revista Estudos Históricos, Rio de Janeiro, v. 1, n. . 27, p. 84-109, ago. 2001. Acesso em: 19 abr. 2020.

JORDAN DE ALBARRACIN, Betty. Documentos para una Historia del Derecho Constitucional Boliviano. La Paz: Talleres Gráficos "San Antonio", 1978.

LIMA, Ivana; GRINBERG, Keila; REIS, Daniel (orgs.). Instituições nefandas [recurso eletrônico]: o fim da escravidão e da servidão no Brasil, nos Estados Unidos e na Rússia. Rio de Janeiro: Fundação Casa de Rui Barbosa, 2018.

LIMA, Rafael P. de. A nefanda pirataria de carne humana: escravizações ilegais e relações políticas na fronteira do Brasil meridional (1851-1868). Dissertação (Mestrado) - PPGH, UFRGS, Porto Alegre. 2010.

LINEBAUGH, Peter. Réplica. Revista Brasileira de História, São Paulo, v. 8, n. ${ }^{\circ}$ 16, p. 221-231, mar., ago. 1988. p. 228-231. Disponível em: <https://www.anpuh.org/ revistabrasileira/view?ID REVISTA BRASILEIRA=25>. Acesso em: 5 fev. 2019.

MEIRELES, Denise Maldi. Guardiães da Fronteira: rio Guaporé, século XVIII. Petrópolis: Vozes, 1989.

MOURA, Clóvis. Rebeliões da senzala: quilombos, insurreições, guerrilhas. Porto Alegre: Mercado Aberto, 1988.

NOGUEIRA, Shirley. "A soldadesca desenfreada": politização militar no Grão-Pará da Era da Independência (1790-1850). Tese (Doutorado em História) - PPGH, UFBA, 2009.

PATTERSON, Orlando. Slavery and Social Death: a Comparative Study. Cambridge, MA: Harvard University Press, 1982.

PEABODY, Sue. There are no slaves in France: the political culture of race and slavery in the Ancien Régime. New York: Oxford University Press, 1996.

PEREGALLI, Enrique. Recrutamento militarno Brasil colonial. Campinas, SP: Unicamp, 1986.

PETIZ, Silmei. Buscando a liberdade: as fugas de escravos da província de São Pedro para o além-fronteira (1811-1851). Passo Fundo: UPF, 2006.

RAMOS, Arthur. O negro na civilização brasileira. Rio de Janeiro: Casa do Estudante, 1956.

REIS, João José.; GOMES, Flávio. (Orgs.). Liberdade por um fio: história dos quilombos no Brasil. São Paulo: Companhia das Letras, 1996.

REIS, João José; SILVA, Eduardo. Negociação e conflito: a resistência negra no Brasil escravista. São Paulo: Companhia das Letras, 1989. 
RICCI, Magda. Cabanagem, cidadania e identidade revolucionária: o problema do patriotismo na Amazônia entre 1835 e 1840. Tempo: Revista do Departamento de História da UFF, Niterói, v. 11, n. 22 (Cidadania e Pobreza), p. 5-8, jan. 2007. DOI disponível em: <http://dx.doi.org/10.1590/S1413-77042007000100002. Acesso em: 12 mar. 2018.

ROBERTS, Neil. Freedom as Marronage. Chicago: The University of Chicago Press, 2015.

ROMANI, Carlo; MENEGAT, Carla; ARANHA, Bruno (orgs.). Fronteiras e territorialidades: miradas sul-americanas da Amazônia à Patagônia. São Paulo: Intermeios; Brasília: CAPES; Rio de Janeiro: GT Fronteiras e Territorialidades, 2019.

SALLES, Vicente. O negro no Pará sob o regime da escravidão. Rio de Janeiro: FGV; UFPA, 1971.

SCHWARTZ, Stuart. Escravos, Roceiros e Rebeldes. Bauru, SP: Edusc, 2001.

SCOTT, Rebecca. Degrees of Freedom: Louisiana and Cuba after Slavery. Cambridge, MA: The Belknap Press of Harvard University Press, 2005.

SECRETO, María Verónica. Soltando-se das mãos: liberdades dos escravos na América espanhola. In: AZEVEDO, Cecilia; RAMINELLI, Ronald (orgs.). História das américas: novas perspectivas. Rio de Janeiro: Editora FGV, 2011.

SILVA, Martiniano José. Quilombos do Brasil Central: violência e resistência escrava (17191888). Goiânia: Kelps, 2003.

SILVA, Martiniano José. Resistência dos quilombos no Brasil Central. In: MOURA, Clóvis (org.). Os quilombos na dinâmica social do Brasil. Maceió: EDUFAL, 2001.

VOLPATO, Luiza. Quilombos em Mato Grosso: resistência negra em áreas de fronteira. In: REIS, João José; GOMES, Flávio (orgs.) Liberdade por um fio: história dos quilombos no Brasil. São Paulo: Companhia das Letras, 1996.

VOLPATO, Luiza. A conquista da terra no universo da pobreza: formação da fronteira oeste do Brasil, 1719-1819. São Paulo: Hucitec; Brasília, DF, INL, 1987.

XAVIER, Regina (org.). Escravidão e liberdade: temas, problemas e perspectivas de análise. São Paulo: Alameda, 2012.

Recebido: 17/08/2019 - Aprovado: 29/05/2020

Editores Responsáveis

Júlio Pimentel Pinto e Flavio de Campos 